\title{
Primary Care and Environmental Issues: Unused Medicines and Health Community Agent Intervention in the South of Brazil
}

\author{
Andre Preissler Loureiro Chaves ${ }^{1,{ }^{*}, \#}$, Jamile Machado Hallam ${ }^{2}$ and Louise Marguerite Jeanty de Seixas ${ }^{3}$ \\ ${ }^{I}$ Post Graduate Program in Public Health, ULBRA University, Brazil; ${ }^{2}$ Environmental Engineer, ULBRA University, \\ Brazil; ${ }^{3}$ UFRGS University, Faculty of Pharmacy, Brazil
}

\begin{abstract}
Current Brazilian law does not provide appropriate legislation governing waste resulting from unused medication, which presents a growing public health threat. Studies that have considered these issues are incomplete, classifying unused medication as a remnant of healthcare and ignoring the user, who has the largest role in generating this type of waste. Users do not possess sufficient knowledge regarding the issue or their responsibilities with respect to environmentally appropriate disposal. The main objective of this study was to create a reverse logistics medication channel in a model experiment involving health community agents working in Family Health Strategy teams in Vila Bras, São Leopoldo, Brazil. The community health agents were trained in the appropriate disposal of unused medication and conveyed details of the basic disposal guidelines to the residents of the area served by the teams. The community health agents' activities served a proactive reverse logistics channel, which had vast potential, as the prevention of inappropriate disposal of unused medication increased exponentially.
\end{abstract}

Keywords: Community health agents, drug contamination, health residue management, medication desuetude, medication in the environment, reverse logistics.

\section{INTRODUCTION}

Some aspects of industrial technology involving production systems are polluting nature, using air, water, and soil as the final destination of their effluents, many of which are without treatment or remediation. Environmental problems related to the disposal of various types of waste have been widely discussed, but the disposal of unused drugs (intentional or not) deserves special attention.

With respect to drugs, this waste's first mode of entry into the environment is provided by direct release into domestic, treated, or untreated sewerage and waterways. However, other factors should also be considered [1]: the effluents produced by pharmaceutical industries, rural effluents, the presence of drugs in animal manure used for soil fertilization, and the improper disposal of drugs subsequent to their expiration dates.

The medication user also makes a contribution, albeit minor, to contamination in the system. It should be noted that many medications cause the same environmental damage when used as intended [2]. Some components are excreted in faeces and urine; between $50 \%$ and $90 \%$ of each dose is excreted without modification and remains in the environment.

A study conducted in the state of São Paulo [3] aimed to assess the medication disposal procedure adopted by the

*Address correspondence to this author at the Conde de Porto Alegre Sreet, 550, apt.1801. Porto Alegre, RS, CEP: 90220210, Brazil; Tel: +55 51 3462.9568; Fax: +55 51 3477.1313; E-mail: andreplc@terra.com.br \#This author is currently a visiting researcher at the Centre for Environmental Strategy, University of Surrey, Guildford, UK inhabitants of São Paulo. This study found that, of the 1,009 respondents, $75.32 \%$ discarded expired medication via their household waste, and $6.43 \%$ used the sink or toilet for disposal. Of the total respondents, $63.3 \%$ reported that they were aware of the risks involved in this practice; however, $92.5 \%$ did not enquire as to how to dispose of medication appropriately. This finding concerning lack of guidance and users' non-adherence to proper disposal methods emphasizes the important role that health professionals play in providing instructions in order to minimize the negative aspects arising from this practice [3].

This study proposes an alternative to the reverse logistics (RL) channel for medicine disposal; the proposed project includes enlisting community health workers as facilitators in the process, which involves consumers. It acts as a means of educating users and increasing their awareness, thereby encouraging them to adopt the appropriate disposal of the medicines when necessary.

\section{OVERVIEW OF SURPLUS MEDICINES}

In approaching the subject of medicine disposal, one should first understand the reasons why there is a need for disposal; as all drugs should be consumed according to a prescribed regimen, this need should not exist. Discontinuation of treatment, particularly after symptoms cease, is one reason that people accumulate medication. Even with a proper prescription, there are no guarantees of strict adherence to treatment guidelines. If the dosage is not administered properly, a surplus of medicine is inevitable [4].

In their urgency to alleviate the discomfort caused by unpleasant symptoms, people acquire medicines, do not use the 
entire quantity, and store the surplus for later use. Many of these medicines ultimately lose their validity and are flushed down the toilet or disposed of in household waste [2].

When speaking of inventories maintained by the users in order to understand their motives and their origin, users' behaviour may be due to the following [5]:

- Inadequate product packaging: for example, if the user is prescribed a course of antibiotic treatment that requires 21 tablets, and the package to be sold contains 28 , the remaining 7 tablets will not be used soon after finishing treatment.

- Adverse drug reactions: in this situation, the individual needs to discontinue the medication; failure to do so could lead to further use, resulting in the recurrence of the original effects.

- Failure/interruption of treatment: this occurs most commonly with chronic use of medications such as antihypertensives or antiretrovirals.

- Self-medication: the use of non-prescription drugs, which can lead to numerous problems and is directly related to the item below.

- Homemade pharmacy: this is the "stock" of drugs stored at home, consisting mainly medicines purchased for conditions such as headache, fever, or stomach ache, which are intended for use according to need, or drugs that an individual uses continually and purchases in quantities that will last for several months

- Free samples: these are often (when the individual is not a chronic medication user) forgotten in the home pharmacy store.

After their expiration dates [6], accrued and unused medications should be discarded to avoid problems such as poisoning, use without need or indication, lack of treatment effectiveness, and adverse reactions.

\section{ENVIRONMENTAL IMPACT}

The first studies examining the presence of pharmaceuticals in the environment date back to the 1970s, when Garrison et al. (1976) and Hignite and Azarnoff, (1977) analysed wastewater, or sewage, treatment plants in the United States [7]. They detected the presence of clofibric acid, a metabolite of clofibrate and antilipemic etofibrate.

Studies examining the effluents of 5 Canadian cities found 7 different types of antibiotic medicine. Antibiotics constitute the largest category of drugs used in human and veterinary medicine [8]. This contamination could have been caused by the improper disposal of the medication; the excretion of metabolites, which are not eliminated by the sewage treatment process; or veterinary use [9].

The concern regarding rising levels of pharmaceutical waste found in sewage treatment stations is present in several countries. All of the researchers who conducted the studies mentioned above stressed their concern regarding future consequences and the need to develop new techniques and procedures to reduce or eliminate these effluents from the environment, which is considered feasible.
Contamination of the aquatic environment by residual drugs can occur as a result of the use of manure as fertilizer. The contamination of underground water can also occur due to the use of the digestive sludge, which is loaded with antibiotics used and excreted by animals, from sewage treatment stations in agriculture [10]. Another source of environmental contamination is the disposal of waste from pharmaceutical industries in landfills, which contaminate the underground water in the vicinity of the landfill.

Regardless of whether the source of the generation of pharmaceutical waste is human or veterinary medicine or industries, surplus medicines are invariably found in soil and water, and have the potential to severely alter our quality of life and affect wider environmental health [10].

The presence of 36 different drugs, including therapeutic classes such as antilipidemics, analgesic-antipyretics, antiinflammatories, and anti-hypertensives, was identified by Ternes (1998) in various rivers in Germany. Drug concentrations above $1 \mu / 1$ in aquatic environments were also observed in the United Kingdom [9].

This situation has worsened, as the drugs that are currently produced are designed to remain stable and maintain their chemical properties for a period of sufficient duration to allow them to accomplish their therapeutic functions. A study conducted by Mulroy (2001) [10] found that 50-90\% of a dose of a drug is excreted unchanged in the environment. This characteristic hinders their elimination during the conventional wastewater treatment process.

To Kummerer (2001) [10], some groups of residual medicines, such as antibiotics and oestrogens, deserve more attention. Antibiotics have been discussed extensively because of their contribution to the development of resistant bacteria in the environment and their interchangeability between human and veterinary medicine.

With respect to oestrogens, their possible adverse effects, such as interference in the development and reproduction of aquatic organisms and their relationship with the development of some types of cancers in humans, should be considered. A study of young fish that had been exposed to synthetic oestrogens and other endocrine disruptors demonstrated feminization in male fish [1].

The occurrence of residual pharmaceuticals in sewage and natural waters has become a topic of international importance. Studies have shown that these drugs and their metabolites are found in aquatic environments in several countries besides Brazil, such as Germany, Canada, Holland, Italy, Sweden, the United States, and the United Kingdom [10].

\section{REVERSE LOGISTICS}

The first quote on RL was published in the early 1970s. The term 'reverse distribution' was used by Zikmund and Stanton (1971) at the University of Colorado in the United States. These terms referred to the existing similarities between logistic and the concept of distribution when applied as a reverse production chain (i.e. the consumer to the producer). The reverse distribution channels had already been established by Ginter and Starling in 1978, placing ecological and economic issues first due to the material recovery process $[11,12]$. 
In the 1980 s, a more solid understanding of the relationship between reverse logistics and the environment was established, as both Lambert and Stock (1981), and Barnes (1982), associated RL with recycling and highlighted the benefits to society [12].

The opportunity to reuse materials established a new process flow, reversing the direction of the chain, which is now part of the final consumer and supplier ends. Collectively, steps taken by the product in the opposite direction to that of the direct flow of the supply chain are called RL [13$15]$.

\section{FAMILY HEALTH STRATEGY}

In December 1993, the Ministry of Health and the United Nations Children's Fund (UNICEF) organized a meeting regarding 'family health' in Brasilia, Brazil, through which the Family Health Program was designed [16]. The Family Health Program, given its characteristics, escapes the usual programs by characterizing itself as a strategy that enables integration and promotes the organization of activities in a defined territory in order to face and solve the problems identified.

Family Health is understood as a strategy for reorienting the care model, operationalized through the implementation of multidisciplinary teams in primary healthcare units. These teams are responsible for monitoring a set of families in a defined geographical area [17]. The teams are assigned the task of health promotion, the prevention of diseases and frequent disorders, patient recovery and rehabilitation, and the maintenance of health in the community. Family health teams are responsible for monitoring the wellbeing of families and required to push the classically defined boundaries in primary care in Brazil, particularly in the context of the Unified Health System (SUS) [17].

The work of the Family health teams is key to the ongoing search for communication and exchange of experiences and knowledge between team members, and this information is also shared with community health agents (CHAs). As the very least, teams consist of a family doctor, a nurse, a nursing assistant, and 6 CHAs. When expanded, they also include a dentist, dental assistant, and dental hygienist.

Each team is responsible for monitoring a recommended average of 3,000 and a maximum of 4,000 residents of a particular area, and they share the responsibility for healthcare. The teams are engaged primarily in basic health units, homes, and the community. They are characterized as an input port within a hierarchical regionalized health system, with defined territory and responsibility for a defined population. It is also worth considering the risk factors to which the community is exposed; the teams provide integral, permanent, quality care and conduct educational activities and health promotion based on these risk factors [17].

Working as intended, the family health teams are able to solve $85 \%$ of the health problems in their community, providing quality care, preventing diseases, avoiding unnecessary hospitalization, and improving the population's quality of life [16]. In visiting families, attention is directed to pre-established programs such as nursing, hypertension, and certain types of preventive care, for endemic disease in the region.

\section{COMMUNITY HEALTH AGENTS}

The program CHAs are considered part of the Family Health Strategy. The actions of community health workers are supervised and guided by a nurse/supervisor stationed at a basic health unit. The community health workers can be found in 2 different positions in relation to the public health system:

a) Connected to a basic health unit that is still to be organized in according with the Family Health Strategy

b) Linked to a basic family health unit as a member of the multidisciplinary team

A total of 204,000 CHAs are active in the country, covering its activities in rural communities, urban neighbourhoods, and highly urbanized and industrialized regions [17].

Ministerial Decree 648, of 28 March 2006, which was approved the National Policy for Primary Care, established a review of guidelines and standards for the organization of primary care in the Family Health Program and the Community Health Agents Program [18]. The number of CHAs should be sufficient to cover $100 \%$ of the enrolled population, with a maximum of 750 people per agent and 12 agents per family health team.

The CHA is the link between residents and the Family Health Strategy. Required to reside in the locality of action, they understand the problems faced by the community and the demands and needs that are peculiar to each user. Access to users' homes is easier because of this proximity, allowing all CHAs to understand the problems faced by families [19].

\section{MATERIAL AND METHODOLOGY}

\section{The Vila Bras Neighbourhood}

Vila Bras is located within the Santos Dumont District, in the City of Sao Leopoldo, Brazil, and has a population of approximately 12,000 inhabitants [20].

Primary healthcare in the neighbourhood is administered from the Family Health Strategy Headquarters (Fig. 1). If there is a need for a consultation with a specialist, patients are referred to the basic health unit, which contains the necessary specialist.

Two Family Health Strategy teams, Bras I and Bras II, are also based at this basic family health unit. In addition to health professionals, each team includes a doctor, dentist, nurse, nursing technician, and dental assistant, with 8 health community agents.

Each CHA is responsible for a micro-area, so that each agent has between 400 and 750 people under his or her care. According to the municipal coordination of the program, the 2 teams from Vila Bras include approximately 7,393 families in total. The target coverage of service users by each agent is $80 \%$, and for hypertensive and diabetic patients, care should be provided in $100 \%$ of cases.

\section{Training of Health Community Agents}

On 8 September 2011 , of the 16 health community agents (members of the Bras I and Bras II teams), 12 were present at the district health department building and completed a 
training course lasting 2 hours. A health professional team was also in attendance to assist in coaching the agents.

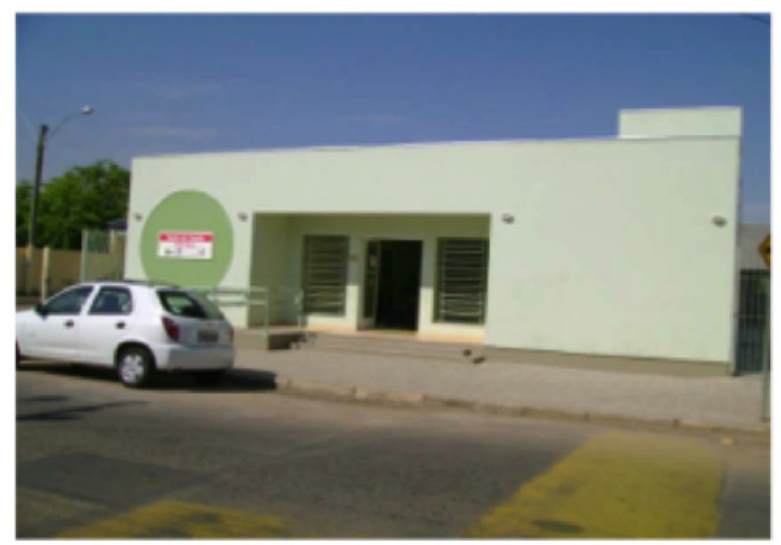

Fig. (1). Basic family health unit in vila bras [21].

With the help of the pharmaceutical municipality, relevant environmental and public health aspects of the disposal of drugs were addressed. As the agents were only educated to elementary school level, simple language and techniques were employed to facilitate understanding (Fig. 2).

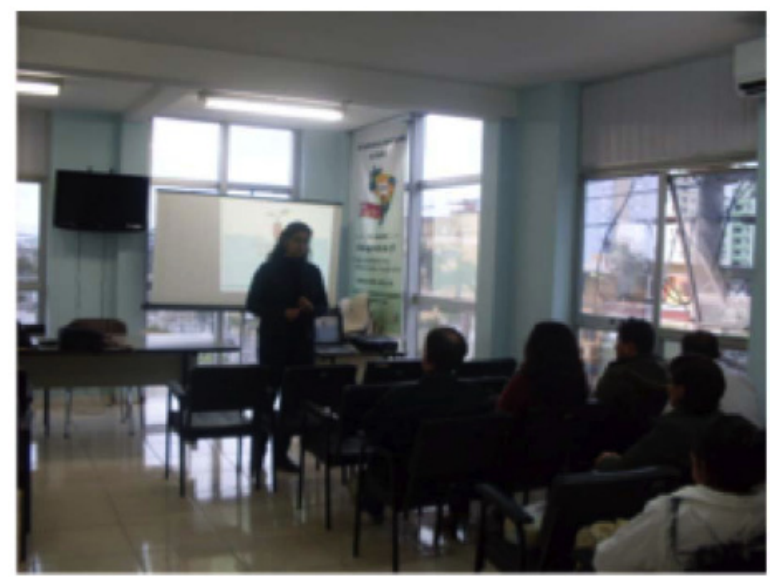

Fig. (2). Training for health community agents.

Among the issues cited, the environmental risks of improper disposal, risks of domestic accidents, health risks in self-medication cases, forms of packaging, and proper storage of medication were addressed. The training was conducted with the aid of audiovisual material. The agents were able to correctly identify the validity of the drug in its different forms (Fig. 3).

As the validity of each type of medication may have been registered in different locations, agents observed and handled such products in order to familiarize themselves with this situation. Practical training was also provided via assisted CHA visits, but due to time constraints, this was not possible.

\section{Pilot Project for Medication Collections}

The collection of unused medicines was performed over a period of 60 days, from 9 September to 8 November 2001. No restrictions were in place with respect to the families visited; this applied to all visits made by agents within the period. In addition, the drugs that were collected were not subject to any filters with respect to therapeutic class or packaging. Collection of the unused drugs was performed via the direct intervention of the CHAs during their routine visits. During the visit, they asked residents to show the agents where the drugs were stored and identified and collected those that were no longer required, regardless of whether the expiration date had passed. Oral informed consent was obtained from the study participants, as there was an unavoidable risk of breach of privacy.

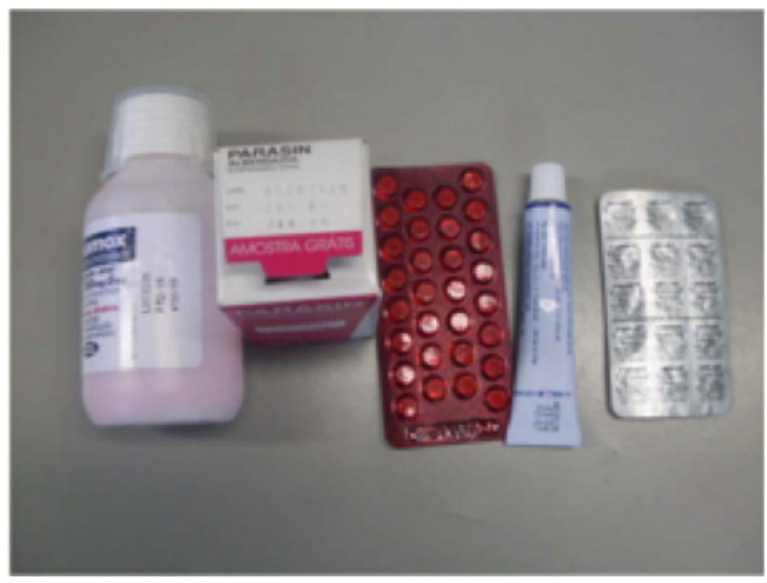

Fig. (3). Drugs used in training.

Each family was eventually visited at least twice, but the issue of drug disposal was addressed during only once. The basic guidelines regarding the problems caused by the consumption of such drugs were provided to the user by the agent, and when more technical questions arose, these were directed to health professionals at the unit.

Following the visits, the agents returned to the Family Health Strategy headquarters at Vila Bras and were told to pack the material collected (Fig. 4) and place it in an on-site location to which only the agents and the unit staff had access.

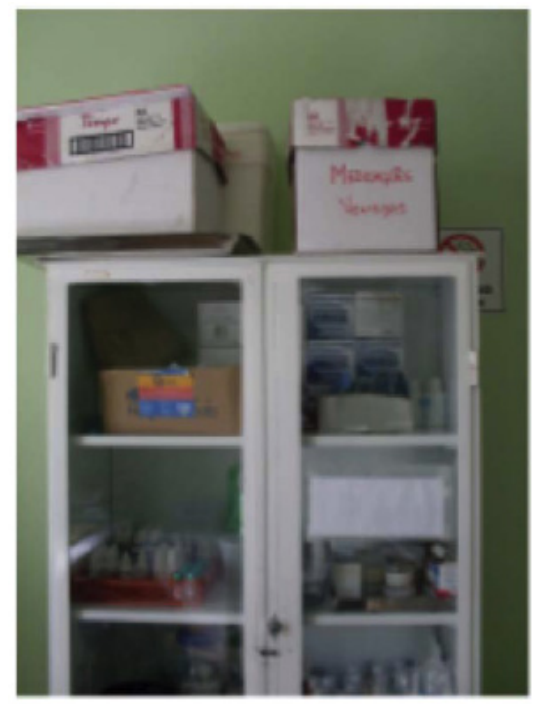

Fig. (4). Stores of medicines collected by agents, located at the family health strategy headquarter. 
The products were then separated according to type. The waste was deposited in a solid box and consisted of capsules, tablets, ointments, and other medicines in the form of liquids such as syrups, sprays, and homeopathic remedies. This measure was taken to ensure security, due to the risk of leaks and possible chemical reactions between the products.

When the experiment concluded, the material was collected by a civil servant and forwarded to the pharmacy to be identified, quantified, and packaged. Data were entered and tabulated using Microsoft Office Excel 2007.

On 8 November 2011, the agents attended a meeting regarding Family Health Strategy coordination to evaluate the results obtained and identify possible gaps and opportunities for improvement.

\section{RESULTS AND DISCUSSION}

Following the 60 days during which medication was collected, 16 CHAs made approximately 2,800 visits to households in the 8 areas included in the study. Thirty different therapeutic classes of drugs were collected, the most common of which were tablets. Most of the drugs collected were diuretics, antihypertensives, and vasodilators intended for continued use. This finding can be attributed to the fact that agents must meet $100 \%$ collection rates for hypertensive and diabetic patients. Fig. (5) shows the most common therapeutic classes collected during the campaign.

In the analysis of the commonly collected antihypertensive drug classes (Fig. 5), antibiotics, analgesics, and antiinflammatories stood out as being collected most frequently. However, other classes of considerable environmental impact, such as contraceptives, were also collected. Therapeutic classes that were collected only once were ignored.

The greater abundance of antibiotics reaffirms the importance of the topic already mentioned in the literature [10]. This high figure reflects the potential for generation of this waste in homes, the difficulty surrounding treatment adherence, and the risk of self-medication and associated problems.

A study by Ribeiro and Heineck (2010) [22] identified the drugs stocked by residents visited by the Family Health Strategy in Minas Gerais, Brazil. In the study, 285 families were visited, and approximately 406 expired products were found, comprising $18.5 \%$ of the total number of drugs collected. In comparison to these findings, the number of medications collected in the present study could be considered low. In addition, one can view the low result as a function of the total population visited and its potential for generating this type of waste, as many children and elderly people live in the area.

With respect to the age of participants in the same study [22], 11\% of the drugs stocked, regardless of whether the expiration dates had passed, belonged to children or younger adults, and $21.13-67.8 \%$ belonged to the elderly. A high likelihood of expired medications lying undiscovered in the home could be inferred from this comparative reference and social data from São Leopoldo.

The CHAs reported difficulty in accessing locations in which users stockpiled their medications. Many residents stated that they did not have unused drugs because they had adhered to their prescribed treatment. When asked how they had broached the subject with users, many of the CHAs reported that they had asked to see the location in which the drugs were stored. As the agents normally focus on patients' health problems, they reported that users often showed them only those medications used in their current treatment.

The results regarding the therapeutic classes of drugs differed according to the approach adopted by the CHA. According to the report submitted by one of the agents, she asked whether anyone in the family had received any medical treatment, citing sore throats, sinusitis, colds, and pain. With this approach, the agent was able to find a larger number of antibiotics and anti-inflammatories.

When CHAs were asked about the scope of the application of their practice, they indicated that they preferred to approach patients whom they knew were undergoing treatment. Again, this is one of the justifications for the high numbers of drugs intended for continued use found in all therapeutic classes.

All of the medicine collected was sent to the Municipal Pharmacy, where it was stored until a minimum volume had been reached and disposal was economically viable. The

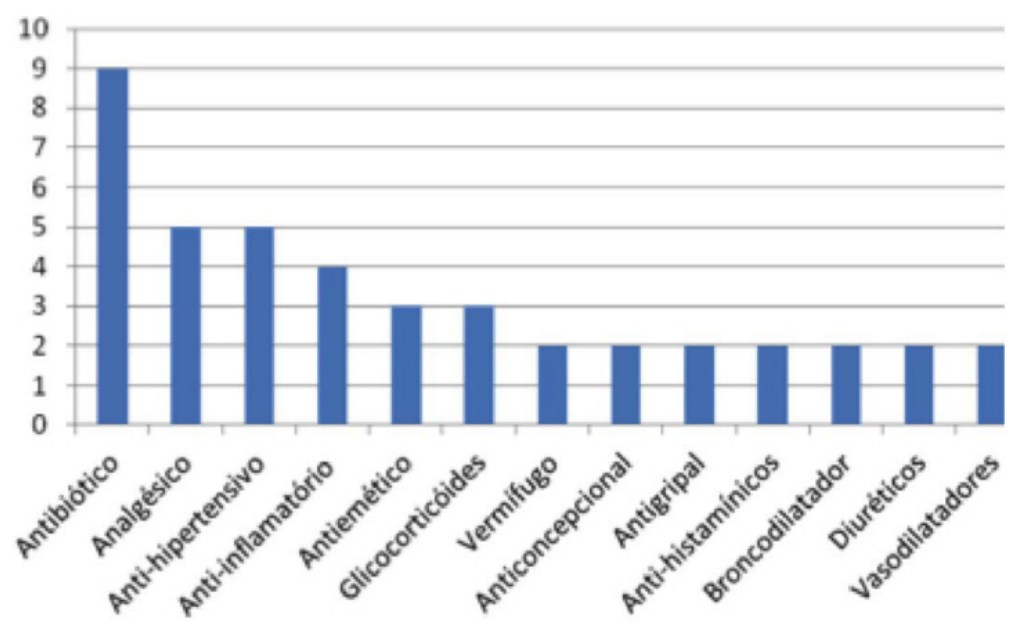

Fig. (5). Occurrence of the collection of therapeutic classes in the medication collection. 
responsibility for payment for the final disposal of the medicine rests with the Municipality of São Leopoldo's company of choice, hired following a bidding process.

The team consisted of 16 participants, of whom only 12 attended training. This may have affected the outcome of the medicine collection, as the 4 participants who did not attend training received information conveyed informally by colleagues, and their understanding may have been compromised, as the collection had not been afforded due importance.

According to reports concerning Family Health Strategy coordination, the CHA program was not always adhered to strictly by the agents, fact directly decisive for its success. The low level of education required, when the agents are selected, is a factor for consideration, because they may not be in a position to appreciate the real extent of the problem.

CHAs were not accompanied by health professionals during visits to residents who had agreed to take part in the study. Aside from the community intervention led by the CHAs, there was no means of campaign promotion and dissemination.

\section{Opportunities for Improvement}

Some aspects to improve the efficiency of the program, when implemented in large scale, can be listed.

- Accompanying health professionals during visits: Use visits by healthcare professionals in conjunction with CHAs, to address the issue with local residents. This measure could improve the agent's credibility with the user, who would be treated by a top-level professional, promoting greater treatment adherence in the population.

- Preparation of graphic educational material: This type of material could be distributed by various professional units and under different circumstances. It could be available in the reception unit, delivered by doctors along with prescriptions, or delivered to users by CHAs during routine visits.

- Posters Unit: Display posters informing users that the unit receives this type of waste and requesting that users take unused medicines or deliver them to the CHAs.

- Motivation of CHAs: CHAs could be offered incentives, with those who obtain superior results in the medicine collection undertaking rewarded at the end of a given period.

- Recycling CHAs: Promote regular meetings that address recent difficulties, to ensure that analysis cycles are shorter. This measure could optimize the results, as it would allow faster resolution of problems.

- Approach: It was evident that the approach that CHAs adopted exerted a direct influence on the results. Users should be asked about other types of medications and treatments, not only their own but also those used by other family members.

- Interview script: An interview tool used to ensure that the approach to be adopted is standardized. The tool could be built in conjunction with the CHAs and health professionals, to allow prediction of possible user responses.
Refinement of the campaign, either partially or entirely, and adopting the suggested measures would improve results with respect to the number of medications collected and the quality of the information generated.

\section{CONCLUSION}

This study aimed to create a channel for reverse logistics of medicines via an intervention provided for service users by health community agents and Family Health Strategy teams (Bras I and Bras II) in Vila Bras, São Leopoldo, Brazil. The study included training health community agents to collect medicines and correctly address the issue of inappropriate medicine disposal with service users. The determinant factor in achieving satisfactory results for the program was the training and motivation of the agents. The different approaches adopted by agents generated different results. The relevance of the subject should be emphasized when training the agents to enable them to convey relevant information to users and ensure that the issue is afforded due importance.

Practical training, informed by requests made by $\mathrm{CHAs}$, should be implemented in conjunction with health professionals' monitoring of CHAs during team visits made as part of users' treatment. An assessment tool should be used to assess CHAs' understanding of the topic at the end of training and promote periodic retraining.

As a means of encompassing the entire chain of reverse logistics of drugs in the city, the municipal pharmacy's management should be changed, as the method used at present is not considered appropriate. The existing waste management plan should be reviewed in order to identify the factors that are not covered with regard to the standard requirements. Adopting an attitude beyond legal compliance will bring benefits such as reductions in both cost and risk to workers health.

The search for an efficient reverse logistics channel for these products is valid, given the lack of user knowledge and the need to maintain users' safety. To dispense with the use of agents to perform this practice, one can reach the users directly by promoting environmental education programmes for the target population.

Another approach that could be adopted involves disclosure by health professionals, such as doctors and nurses, who have direct contact with users and displaying posters in the basic health unit, to inform users that there is a collection point for surplus medicines.

This work can be considered relevant and applicable to other Family Health Strategy teams in the municipality. Its importance lies in the necessity to create mechanisms for reverse logistics channelling of drugs into disposal, acting as a means of providing education for the population served by the team. It is a proactive tool, as it works directly and at the source, preventing additional drugs from reaching this dangerous condition.

\section{CONFLICT OF INTEREST}

The authors confirm that this article content has no conflict of interest. 


\section{ACKNOWLEDGEMENTS}

We wish to thank the Borough of São Leopoldo, the Department of Public Health, the community health workers, and the population of Vila Bras.

\section{REFERENCES}

[1] Melo SAS, Trovó AG, Bautitz IR, Nogueira RFP. Degradation of residual pharmaceuticals by advanced oxidation processes. Quim Nova 2009, 32(1): 188-97 [Retrieved 2011 Aug 24]. Available from: http://www.scielo.br/pdf/qn/v32n1/v32n1a34.pdf

[2] Ueda J, Tavernaro R, Marostega V, Pavan W. Environmental impact of drugs disposal and study of population awareness about the problem. Revista Ciências do Ambiente On-Line 2009; 5(1) [Retrieved 2014 Oct 29]. Available from: http://fga.unb.br/ articles/0000/2227/ect2011.pdf

[3] Melo V, Neves NDDM, Paio MDA, et al. Waste management in pharmacies and drugstores of the São Paulo City 2005 [Retrieved 2014 Oct 29]. Available from: http://www.oswaldocruz.br/ download/artigos/saude21.pdf

[4] Alvarenga LSV, Nicoletti MA. Domestic dispose of medicines and some considerations about the environmental impact. Revista Saúde 2010; 4(3): 34 .

[5] Ribeiro MA, Binsfeld PC. Dispose of expired or unused drugs: risks and recent advances: In: Proceedings of the Exhibition of Scientific Production of the Post Graduation Lato Sensu Courses. Goiania: Pontifical Catholic University of Goias, Brazil, 2013.

[6] Bellan N, Pinto TJA, Kaneko TM, Moretto LD, Junior NS. Critical analyzis of the regulations regarding the disposal of medication waste. Braz J Pharm Sci 2012, 48(3): 507-18 [Retrieved 2014 Oct 30]. Available from: http://www.scielo.br/scielo.php? script=sci_arttext\&pid=S1984-82502012000300018\&lng=en

[7] US Environmental Protection Agency. Bureau of Water. Report on pharmaceuticals and personal care products in Illinois drinking water. Illinois, US: EPA [Online] 2008, [cited 2014]. Available from: http://www.epa.state.il.us/water/pharmaceuticals-in-drinking-water. pdf

[8] Zapparolli ID, Camara MRG, Beck C. Mitigating measures for the pharmaceutical industry in Londrina/PR, Brazil: environmental impact the dumping of wastes in water bodies. In: Proceedings of the $3^{\text {rd }}$ International Workshop Advances in Cleaner Production, São Paulo: Brazil, Federal University of Londrina, 2011.

[9] Eickhoff P, Heineck I, Seixas LMJ. Management and final disposal of medicines: a discussion of the problem. Revista Brasileira de Farmácia 2009; 90(1): 64-8.
[10] Bila DM, Dezotti M. Pharmaceutical drugs in the environment. Quim Nova 2003; 26(4): 523-30 [Retrieved 2011 May 03]. Available from: http://www.scielo.br/pdf/qn/v26n4/16435.pdf

[11] Leite PR. Reverse logistics, environment and competitiveness. São Paulo, Brazil: Pearson Prentice Hall 2008

[12] Santana D. Reverse logistics in carriers of the Rio Grande do Sul State. RACE Revista de Administração, Contabilidade e Economia 2008; 7(2): 187-98.

[13] Daher CE, Silva EPS, Fonseca AP. Reverse logistics: opportunity for cost savings through of the management of the integrated chain of value. BBR Braz Bus Rev 2006; 3(1): 58-73.

[14] Lacerda L. Reverse logistics: an insight into the basic concepts and operating practices [Online]. 2009, [cited 2011]. Available from: http://www.sargas.com.br/site/artigos_pdf/artigo_logistica_reversa leonardo_lacerda.pdf

[15] Resende EL. Channel of reverse distribution in the tire recycling: case study. PhD dissertation. Rio de Janeiro, Brazil: Pontifical Catholic University of Rio de Janeiro 2004.

[16] Rosa WAG, Labate RC. Family health program: the construction of a new care model. Rev Latino-Am Enfermagem 2005, 13(6): 102734 [Retrieved 2014 Oct 30]. Available from: http://www.scielo.br/pdf/rlae/v13n6/v13n6a16.pdf

[17] Brazil. Ministry of Health. Department of Primary Care (DPC) Primary care and the family health strategy [Online]. 2011 [cited 2011]. Available from: http://dab.saude.gov.br/atencaobasica.php

[18] Brazil. Ministry of Health. National Primary Care Policy - revision of guidelines and rules for the organization of primary care: Family Health Programme and Community Health Agents Programme [Online]. 2006. [cited 2011]. Available from: http://portal. saude.gov.br/portal/arquivos/pdf/volume_4_completo.pdf

[19] Silva PR, Ribeiro GTF. Community health agent link between family health strategy community and needy. Vita et Sanitas 2009, 3: 66-85. [Retrieved 2011 Nov 15]. Available from: http://www.fug.edu.br/revista_3/pdf/asc_elodeligacao.pdf

[20] Brazil. Brazilian Institute of Geography and Statistics. National Survey on Basic Sanitation [Online] 2008. [cited 2011]. Available from: http://www.ibge.gov.br/home/estatistica/populacao/ condicaodevida/pnsb2008/PNSB2008.pdf

[21] City of São Leopoldo [Online] 2014. [cited 2014]. Available from: https://www.saoleopoldo.rs.gov.br/home/

[22] Ribeiro MA, Heineck I. Drug storage at home in the community assisted by the Family Health Programme in Ibiá, MG, Brazil. Saúde Soc, 2010; 19(3): 653-63 [Retrieved 2014 Sept 24]. Available from: http://www.scielo.br/pdf/sausoc/v19n3/16.pdf

(C) Chaves et al.; Licensee Bentham Open.

This is an open access article licensed under the terms of the Creative Commons Attribution Non-Commercial License (http://creativecommons.org/licenses/by-nc/3.0/) which permits unrestricted, non-commercial use, distribution and reproduction in any medium, provided the work is properly cited. 